RUNNING HEAD: Strategies for verifying memories

\title{
A robust preference for cheap-and-easy strategies over reliable strategies when verifying personal memories
}

Robert A. Nash¹, Kimberley A. Wade², Maryanne Garry³, \& James S. Adelman²

${ }^{1}$ School of Life and Health Sciences, Aston University, UK

2 Department of Psychology, University of Warwick, UK

${ }^{3}$ School of Psychology, Victoria University of Wellington, New Zealand

Word count: 6619 in main text and footnote

Author note: To access the research data supporting this publication, see

http://dx.doi.org/10.17036/dcf4b463-35fd-41da-8710-b91b5967c2b4

\section{Corresponding author}

Robert A. Nash

School of Life and Health Sciences

Aston University

Birmingham B4 7ET

United Kingdom

r.nash1@aston.ac.uk

Tel: +44 (0) 1212044522 
People depend on various sources of information when trying to verify their autobiographical memories. Yet recent research shows that people prefer to use cheap-and-easy verification strategies, even when these strategies are not reliable. We examined the robustness of this cheap strategy bias, with scenarios designed to encourage greater emphasis on source reliability. In three experiments, subjects described real (Experiments 1 and 2) or hypothetical (Experiment 3) autobiographical events, and proposed strategies they might use to verify their memories of those events. Subjects also rated the reliability, cost, and the likelihood that they would use each strategy. In line with previous work, we found that the preference for cheap information held when people described how they would verify childhood or recent memories (Experiment 1); personally-important or trivial memories (Experiment 2), and even when the consequences of relying on incorrect information could be significant (Experiment 3). Taken together, our findings fit with an account of source monitoring in which the tendency to trust one's own autobiographical memories can discourage people from systematically testing or accepting strong disconfirmatory evidence.

Keywords: autobiographical memory; nonbelieved memories; false memory; decision-making; cost 


\section{A robust preference for cheap-and-easy strategies over reliable strategies when verifying personal memories}

American news anchor Brian Williams' professional reputation seemed to be in tatters in 2015, when an extraordinary memory he had repeatedly and publicly described — of being inside a helicopter that came under fire in Iraq in 2003-was indisputably proven false (Chabris \& Simons, 2015). Williams' story was reminiscent of countless other cases in which well-known public figures' purported memories have been refuted: Hillary Clinton's recollection of arriving in Bosnia under sniper fire, and George W. Bush's recollection of the moment he learned of the 9/11 terrorist attacks, being just two examples (Greenberg, 2004; Mason, 2008). In each of these cases, the public figures continued to insist that they recalled the events in the way they had described, even after accepting that there was proof to the contrary. Put another way, these public figures held on to their nonbelieved false memories, maintaining their apparently vivid recollections of events long after discovering that those recollections were inaccurate, even fictional (Clark, Nash, Fincham, \& Mazzoni, 2012; Mazzoni, Scoboria, \& Harvey, 2010; Otgaar, Scoboria, \& Mazzoni, 2014; Otgaar, Scoboria, \& Smeets, 2013). Although we now know that nonbelieved memories are surprisingly common (Mazzoni et al., 2010), these high-profile instances raise a puzzling question: given that other people readily found debunking evidence, why didn't Brian Williams, Hillary Clinton, or George W. Bush? How did these well-educated people fail to discover that their own memories were wrong before sharing them so publicly and for so long?

The papers in this special issue all address people's decisions about the accuracy and reliability of their own memories-and about whether or not to 
continue believing in those memories. We know that when people are asked why they stopped fully believing in their own memories, they describe many reasons. The most common reason is social feedback; that is, being told by another person that the remembered event did not happen or could not have happened (Scoboria, Boucher, \& Mazzoni, 2015; see also Mazzoni et al., 2010). Other common reasons include reappraising the plausibility of the event, and discovering physical evidence to the contrary. Nevertheless, in most cases people do not mindlessly abandon memories simply because they are brought into question. Rather, people often look for ways to validate and verify their memories (Ross, 1997; Ross \& Newby, 1996; Wade \& Garry, 2005).

The types of information people use to verify putative memories are often the same types of information that force them to question their memories. For example, most subjects in one study said that if one of their childhood memories were challenged, they would verify that memory by consulting friends or family, or by mentally trawling for confirmatory or disconfirmatory recollections (Wade \& Garry, 2005; see also Arbuthnott, Kealy, \& Ylioja, 2008; Kemp \& Burt, 2006; Wade, Nash, \& Garry, 2014). But how do people decide which of these strategies to use? There is surprisingly very little empirical evidence addressing this question, but we know that the strategies people choose do not always lead to correct decisions. One the one hand, people sometimes place trust in fallible sources, and abandon their genuine memories (Mazzoni, Clark, \& Nash, 2014; Merckelbach, Van Roermund, \& Candel, 2007). On the other hand, people are sometimes unfazed by a lack of corroboration, and continue to believe their false memories even when challenged with contradictory evidence (McNally, 2012; Sheen, Kemp, \& Rubin, 2001). 
To our knowledge, only one study to date has directly examined how people choose strategies, offering insight into why the process of verifying memories often leads to mistaken beliefs. In that study, subjects described a distinctive memory from their childhood, and suggested five strategies for verifying their memory if it were challenged (Wade et al., 2014). Subjects then appraised the reliability (i.e., the likelihood the information they might gain would be trustworthy) and cost (i.e., the extent to which the strategy requires them to expend money, time, effort, and so forth) of using each of those strategies, and the likelihood that they would use each strategy. Their ratings showed that subjects consciously or unconsciously carried out a form of cost/benefit analysis: they typically preferred strategies that were both reliable and "cheap," yet when the two goals of maximizing reliability and minimizing costs conflicted, they were biased towards cheap strategies over reliable ones.

The notion that people eschew reliable information about their own pasts in exchange for cheap and easy-to-access information may account for why wellknown public figures sometimes share their false memories with the world. In theoretical terms, this "cheap strategy bias" fits well with the "Principle of Least Effort," which proposes that people aim to achieve their goals in ways that minimize cognitive and physical expenditure (Allport, 1954; Eagly \& Chaiken, 1993; Zipf, 1949/1972). This Principle of Least Effort is also mirrored in Fiske and Taylor's (1984) depiction of people as "cognitive misers," who are driven to rely on cheap heuristics when making decisions. Empirical data support these theoretical accounts, showing that even people's most simple behaviors are instinctively attuned to minimize effort (Kool, McGuire, Rosen, \& Botvinick, 2010). For example, our physical movements when walking and when climbing 
stairs minimize the metabolic energy expended (Selinger, O’Connor, Wong, \& Donelan, 2015; Sparrow \& Newell, 1990). Indeed, when people try to reconstruct personal experiences that they do not remember, they often turn to easilyaccessible yet unreliable sources (Nash \& Takarangi, 2011).

Nevertheless, the idea that we lean on cheap strategies seems improbable when we consider the great importance people place on autobiographical memories that provide an authentic and stable sense of self, and when we consider the importance of authenticity to people's general wellbeing (Bluck \& Alea, 2008; Sheldon, Ryan, Rawsthorne, \& Ilardi, 1997; Sutin \& Robins, 2008). For example, most people say they would not want a drug to dampen the emotional intensity of a traumatic memory, nor a therapy that would provide them with false yet "beneficial" memories (Nash, Berkowitz, \& Roche, under review; Newman, Berkowitz, Nelson, Garry, \& Loftus, 2011). One reason many people give for opposing these treatments is a concern that artificially distorted memories would lead their thoughts and personalities to be inauthentic. Given that people are so resistant to having distorted memories, even when those memories could potentially be beneficial, it is surprising that people are then unwilling to avoid memory errors by investing in reliable verification strategies.

\section{Do people consistently prioritize cheap over reliable strategies?}

Although Wade et al.'s (2014) findings provide support for a cheap strategy bias, there are reasons to expect that this bias would apply only to quite specific types of autobiographical events. In the experiments we report here, our aim was therefore to examine the robustness of the cheap strategy bias, using scenarios in which we might expect the bias to be weakened or even reversed. In each of our three experiments, we examined a theoretically-grounded, discrete 
factor that could lead people away from cost-based decision strategies and towards using reliable sources. Specifically, in Experiment 1 we manipulated the age of the memory (childhood vs. recent); in Experiment 2 we manipulated the personal importance of the memory (important vs. trivial); and in Experiment 3 we manipulated the motivation for verifying the memory (for giving a police statement vs. for telling a story to one's family). Moreover, to broaden our understanding of memory verification across different kinds of event-memories, rather than just for the kinds of medical memories verified by Wade et al.'s subjects, in all three experiments we gave subjects much greater choice over the memories they described. Overall, we reasoned that if the cheap strategy bias held across all of these different circumstances, then we should have much stronger cause to believe that it represents a robust influence on people's memory verification decisions.

\section{Experiment 1}

In Experiment 1, we examined what would happen to the cheap strategy bias when people considered how they would verify a recent memory, rather than a childhood memory (i.e., the focus of Wade et al., 2014). There is good reason to predict that people would rely on it less. For example, when verifying childhood memories, people may rely on cheap strategies simply because they have so few reliable options. After all, almost any strategy for verifying childhood memories could be described as unreliable, by virtue of the long time-lapse and the associated decay of evidence. If this account is true, then we would expect people to better consider the reliability of their possible strategies when they are instead asked to verify a recent memory, because a greater number of reliable 
strategies are then possible. We would thus expect the cheap strategy bias to be reduced or reversed in these circumstances.

But there are also reasons to make a different prediction about the age of the memory. Regardless of whether or not reliable verifying strategies are available, people should simply have more reason to distrust their childhood memories than to distrust their recent memories - after all, recent memories are typically far more vivid and compelling than are childhood memories (Johnson, Foley, Suengas, \& Raye, 1988). As a result, people may be unwilling to invest much time or effort in verifying recent memories that they already strongly trust. Based on this reasoning, we could predict that the cheap strategy bias would be even larger for recent memories than for childhood memories. In Experiment 1 we investigated these contrasting predictions.

\section{Method}

Subjects and design. A total of 117 undergraduate students took part in exchange for course credit. Of these, we removed 17 from analyses because they failed to follow the task instructions. The final sample comprised 85 females and 15 males, aged 18-28 $(M=19.02, S D=1.34)$. We used a within-subjects design, with Memory (childhood vs. recent) as the within-subjects manipulation.

Procedure. Subjects completed the study online. We told them our aim was to explore the strategies people use to verify their memories, and asked them to think of a real memory from their own lives. We randomized whether subjects were asked first about a childhood memory or recent memory. For childhood memories, we asked subjects to choose an event they remembered well, one that occurred when they were between 5 and 10 years old, and that happened at a specific time and place, rather than an extended event such as a 
vacation. For recent memories, we gave subjects the same instructions, except we stipulated the event should have occurred within the past 12 months. Subjects described their chosen event in detail by typing into a text box.

On the next page of the survey, we asked subjects to imagine they were describing their chosen event to someone, and that the person challenged this memory by suggesting that the event never happened. We then asked subjects to list five strategies they might use to convince themselves, once and for all, whether or not the event truly happened. Then, subjects also described what information they would be looking for when using each of these strategies.

Next, we asked subjects about their five strategies. On one page, subjects saw their five strategies listed, and then rated each strategy on reliability and cost. We told them "reliability" meant the likelihood the information they might gain would be indisputable, trustworthy and accurate $(1=$ Not reliable at all; $5=$ Extremely reliable). We also told them that "cost" meant the extent to which the strategy required them to expend money, time, energy, effort, labor, or aggravation $(1=$ Very small cost; $5=$ Very high cost $)$. On the next page, subjects rated the likelihood that they would pursue each of their five strategies $(1=$ Not at all likely; 5 = Extremely likely), and then identified the one strategy that they would be most likely to try first. We counterbalanced the order in which subjects completed the ratings such that some considered reliability and cost first, followed by likelihood, whereas others considered likelihood first, followed by reliability and cost.

After completing all of these ratings, subjects who had already described a childhood event then described a recent event, and vice versa. Finally, subjects received a written debriefing. 


\section{Results and discussion}

Subjects described a variety of childhood and recent memories, and numerous strategies for verifying those memories. For instance, Subject \#20 described a childhood memory of being unhappy at having to wear a dress for her parents' wedding at age 6 . She proposed verifying the memory by watching through home videos. Subject \#24 described a recent memory of going on a jetski for the first time during her summer vacation. She proposed going jet-skiing again to try to cue more detailed memories. As the top part of Table 1 shows, subjects did not only suggest strategies that they believed would be highly reliable or cheap. Instead, there was considerable variability in ratings of both reliability and cost, and across the dataset there was only a very weak negative association between these two ratings: treating individual strategies as cases, $\mathrm{r}$ $(N=1000)=-.08, \mathrm{p}=.01$

\section{[TABLE 1 ABOUT HERE]}

A research assistant coded all of the strategies into one of six classifications, as shown in Figure 1. A second assistant, who independently coded the full dataset, agreed on $88 \%$ of these classifications (kappa $=.83$ ), therefore the first assistant's judgments were used for our analysis. Overall, the most common type of strategy was to ask other people such as parents or neighbors (46\%). Common strategies also included looking for photos or videos of the event (12\%), or for some other kind of physical evidence such as written letters, or scars (20\%). Subjects sometimes suggested searching for cues to help them remember more, for example by returning to the location of the event (9\%). They also occasionally said they would attempt to remember more details about the event either through mental context reinstatement (2\%), or other 
cognitive techniques such as reflecting on the plausibility of the event (12\%). Figure 1 shows that subjects suggested remarkably similar types of strategy in the recent memory condition as they did in the childhood memory condition (for mean reliability, cost, and likelihood ratings split by type of strategy, see Figure S1 in the online supplemental materials).

[FIGURE 1 ABOUT HERE]

Deciding which strategies to use. The primary aim in this experiment was to examine how the age of a memory influences people's consideration of reliability and cost when choosing memory verification strategies. We also aimed, of course, to replicate our earlier findings showing that although both reliability and cost are important, cost is the primary consideration (Wade et al., 2014). To address these two aims, we analyzed the data using linear mixedeffects modeling (LMM). Like basic linear regression, LMM allows us to predict an outcome variable (here, the rated likelihood of using a strategy) from multiple predictor variables that are not necessarily orthogonal (e.g., the rated reliability and cost of a strategy). Unlike linear regression, though, the LMM approach also allowed us to account for the non-independence of observations that resulted from having five different verification strategies for each subject (see Wade et al., 2014 for more details). In all of the LMM models described in this paper, we standardized all predictor and outcome variables such that the regression coefficients could be interpreted as standardized effect sizes. In all of the models, we also included random intercepts for subject, and for strategy-type (except in Experiment 3, where we did not code the strategy-types), and we included random slopes (per subject) for all within-subject predictors. Because it is difficult to calculate meaningful $p$-values in LMM (as the degrees of freedom in 
each analysis are unclear), we follow the common convention of omitting $p$ values for these LMM analyses, instead treating $|t|>1.96$ as corresponding to a conventional $\alpha=.05$ level of statistical significance (for an example, see Angele, Tran, \& Rayner, 2013).

We found that subjects reported being equally likely to try verifying recent and childhood memories. In line with our earlier work, we also found that subjects were inclined to use strategies that are reliable and cheap (Wade et al., 2014). But we found no evidence that the age of a memory significantly influenced these strategy choices. In particular, the importance of strategies' reliability was similar when verifying childhood memories and when verifying recent memories. Likewise, the importance of cost was similar when verifying childhood memories and when verifying recent memories.

Put in LLM terms, we included these predictors in our model: Memory (childhood vs. recent), Reliability, and Cost, as well as the Reliability x Memory, and the Cost x Memory two-way interactions. Likelihood ratings did not differ between the two levels of Memory, $b=0.03, S E=0.03, t=1.00$. Moreover, Likelihood ratings were positively associated with Reliability, $b=0.26, S E=0.03$, $t=8.06$, and negatively associated with Cost, $b=-0.53, S E=0.04, t=13.76$. There was no significant Reliability x Memory interaction, $b=-0.05, S E=0.03, t=1.80$, nor a Cost x Memory interaction, $b=0.04, S E=0.03, t=1.70$.

This initial LMM analysis tells us that reliability and cost are important independently, but it does not tell us how important they were relative to each other. To look for the existence of a cheap strategy bias, it is necessary to include both reliability and cost ratings in the same analysis. To do this, we conducted a second LMM, which showed that subjects did indeed demonstrate a cheap 
strategy bias. However, we also found that the bias was significantly smaller when verifying childhood memories than when verifying recent memories. This finding might seem to conflict with the results of the first LMM model-in which we found no significant effects of Memory-but it does not. The reason is that in the first LMM model, reliability was slightly (but not significantly) more important in the childhood memory condition than in the recent memory condition, whereas cost was slightly (but not significantly) more important in the recent memory condition than in the childhood memory condition. Because the second LMM model examined both reliability and cost simultaneously, these two nonsignificant effects combined to form a larger and significant effect, whereby the overall cheap strategy bias was greater in the recent memory condition.

In LMM terms, we included four predictors in this second model. The first two predictors were calculated as $z[z$ (Reliability) $-z(-$ Cost $)]$, and as $z[z$ (Reliability) $+z(-$ Cost $)]$, which, for simplicity, we refer to as Attribute difference-ofbetas and Attribute equal-beta, respectively. Note that because $r$ (Likelihood, Reliability) and $r$ (Likelihood, Cost) have opposite signs, the sign of Cost in these equations is negative. When Attributeequal-beta is included as a covariate, the

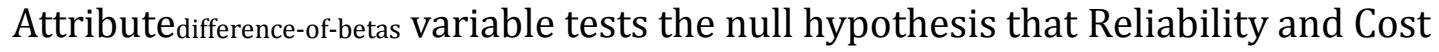
are equally strong predictors of Likelihood. A cheap strategy bias would therefore be indexed by a significant and negative regression coefficient for the

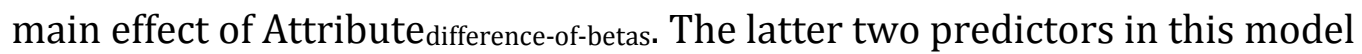
were the two-way interactions of Attribute difference-of-betas $\mathrm{x}$ Memory, and of Attribute equal-beta $\mathrm{X}$ Memory. When the Attribute equal-beta $\mathrm{X}$ Memory interaction is included as a covariate, the Attributedifference-of-betas X Memory interaction tests the null hypothesis that the cheap strategy bias (if it exists) is of equal magnitude in 
the childhood and recent memory conditions. This second model revealed both a significant main effect of Attributedifference-of-betas, $b=-0.18, S E=0.04, t=4.38$, and a significant Attributedifference-of-betas $\mathrm{x}$ Memory interaction, $b=-0.07, S E=0.03, t=$ 2.15.

One question remains unanswered by these two LMMs: did we find the cheap strategy bias both for recent and childhood events, or only for recent events? The answer is that the bias held both for recent and childhood events. Conducting separate LMMs using only the recent memory data, or only the childhood memory data-each with Attribute difference-of-betas $_{\text {and }}$ attribute equal-beta

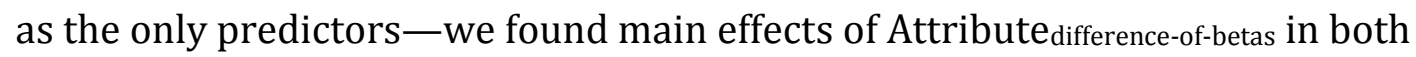
models, each showing that Cost was the stronger predictor of Likelihood (Recent, $b=-0.25, S E=0.05, t=4.64 ;$ Childhood, $b=-0.11, S E=0.05, t=2.28) .{ }^{1}$

In sum, the results of Experiment 1 show that the cheap strategy bias can be replicated and generalized to different kinds of autobiographical memories beyond childhood medical events. The data show that instead of the bias becoming smaller when verifying recent memories, in fact the bias becomes larger. In Experiments 2 and 3, then, we took more direct attempts to undermine

1 Note that we have not reported our analyses of the strategies that subjects said they would be most likely to use first. The reason is that we discovered these data were difficult to interpret. When we analyzed subjects' "most likely" strategies, we found that they were significantly more likely to pick their cheapest strategy than their most reliable strategy-a pattern that held in both conditions of all three of the experiments reported here. But in many cases, subjects reported more than one "cheapest" strategy; that is, they gave more than one strategy with the same lowest cost rating. In contrast, it was less common for subjects to report more than one "most reliable" strategy; that is, subjects tended less often to give multiple strategies with the same highest reliability rating). For this reason, it is difficult to tell whether people chose their cheapest strategy more often because of a cheap strategy bias, or simply because they had a greater statistical probability of picking the cheapest. 
the cheap strategy bias, focusing on circumstances that should make people highly motivated to be accurate.

\section{Experiment 2}

One plausible explanation of the cheap strategy bias is that subjects in Experiment 1 and in Wade et al.'s (2014) study typically chose to describe memories that were not especially important to them, and so subjects were not strongly committed to validating these memories reliably. According to this account, if people were instead to verify a personally important and self-defining memory, then the cheap strategy bias should disappear or reverse, because people should place greater emphasis on maximizing reliability. In Experiment 2 we addressed this idea by asking subjects about the strategies they would use to verify both a personally-important memory and a trivial memory.

\section{Method}

Subjects and design. A total of 116 undergraduate students took part in exchange for course credit. Of these, we removed 12 from analyses because they failed to follow the task instructions, 8 of whom because they rated the importance of their "trivial" event as greater than the importance of their "important" event (see below). The final sample comprised 87 females and 17 males, aged $18-44(M=18.85, S D=2.61)$. We used a within-subjects design, with Importance (important vs. trivial) as the independent variable.

Procedure. The procedure was identical to that of Experiment 1, except that this time we asked subjects to think of both a trivial memory and an important memory. For trivial memories, we asked subjects to think of a relatively trivial event from within the past 12 months, which had no particular impact on their lives. For important memories, we asked them to think of a 
personally significant or important event from within the past 12 months, which had an impact on their lives. We randomized whether subjects were asked first about a trivial memory or an important memory. In addition, immediately after describing each of their memories, subjects rated the personal importance of the event using a sliding scale from 0 (Not at all important) to 100 (Extremely important). Subjects generally rated their important memories as highly important $(M=85.0, S D=16.7)$, and their trivial memories as unimportant $(M=$ 28.5, $S D=21.1), t(103)=23.51, p<.01, d_{\text {unb }}=2.95$.

\section{Results and discussion}

Again, subjects described a variety of memories and verification strategies. For instance, Subject \#4 described an important memory of crashing her car and having to call an ambulance. She proposed trying to find people who had witnessed the accident, and asking them what they remembered. Subject \#50 described a trivial memory of spending the final day of an overseas vacation nursing a hangover. He proposed trying to mentally reinstate his feelings at the time. The middle part of Table 1 shows the distribution of reliability and cost ratings among these various strategies; across the dataset there was only a very weak negative association between the two ratings: treating individual strategies as cases, $r(N=1040)=-.06, p=.08$.

As in Experiment 1, a research assistant coded all of the strategies (see Figure 2). A second assistant, who independently coded the full dataset, agreed on $87 \%$ of classifications (kappa $=.82$ ), so we used the first assistant's judgments for our analysis. Overall, $44 \%$ of strategies involved asking another person. A further $23 \%$ involved looking for photos or videos of the event, and $13 \%$ involved looking for other forms of physical evidence. In total, $16 \%$ of strategies 
involved searching for memory cues, whereas just $1 \%$ involved attempts to remember more details through mental context reinstatement, and $7 \%$ involved other cognitive strategies. Figure 2 shows that subjects suggested similar types of strategies in the important memory condition as in the trivial memory condition (see Figure S2 in the online supplemental materials for mean reliability, cost, and likelihood ratings split by type of strategy).

\section{[FIGURE 2 ABOUT HERE]}

Deciding which strategies to use. Our primary aim in Experiment 2 was to examine the idea that people would be more eager to use reliable strategies, and less eager to use cheap strategies, when the memory in question was personally important rather than trivial. Our analyses showed little support for this idea. All else being equal, subjects said they would be similarly likely to try verifying personally-important and trivial memories, and they were once again motivated to use strategies that were both cheap and reliable. Yet the relationship between Reliability and Likelihood was not meaningfully affected by whether the memory was important or trivial; likewise, the relationship between Cost and Likelihood was not meaningfully affected by whether the memory was important or trivial.

To put these results in LMM terms, we conducted the same initial LMM as in Experiment 1, substituting the Memory variable from that study with Importance (important vs. trivial). This analysis revealed that Likelihood ratings did not differ overall between the two levels of Importance, $b=0.03, S E=0.03, t$ $=1.10$; however, they were again positively associated with Reliability, $b=0.28$, $S E=0.03, t=8.92$, and negatively associated with Cost, $b=-0.51, S E=0.04, t=$ 
12.56. There was no substantial Reliability x Importance interaction, $b=0.02, S E$ $=0.03, t=0.63$, nor a Cost $\mathrm{x}$ Importance interaction, $b=-0.03, S E=0.03, t=1.12$.

Further analysis again confirmed that subjects used a cheap strategy bias. But contrary to our predictions, this bias was almost exactly as large when people verified important memories as when they verified trivial memories. In LMM terms, we repeated the second LMM from Experiment 1, substituting the Memory variable from that study with the Importance variable. This model revealed a main effect of Attribute difference-of-betas, showing that Cost was a better predictor of Likelihood than was Reliability, $b=-0.16, S E=0.04, t=3.96$. However, there was no meaningful Attribute difference-of-betas X Importance interaction, $b=-0.01, S E=0.03, t=0.35$.

Once again, the data from Experiment 2 confirm the primacy of cost considerations in people's choices of verification strategies. Yet these findings also take us further, showing that the bias holds even under circumstances in which we should expect people to have a strong desire to be accurate. Before we can draw this conclusion confidently, though, another interpretation needs testing. Specifically, what motivates people to be accurate when verifying memories might not be whether the memory in question is important to themselves per se, but rather, whether the consequences of being incorrect are important. We considered this related issue in Experiment 3.

\section{Experiment 3}

It is possible that the cheap strategy bias emerged in our prior studies simply because for the particular kinds of memories our subjects described, it would be fairly inconsequential whether these events truly happened or not. In other words, even if low personal significance of the chosen memories cannot 
account for the cheap strategy bias (as the data from Experiment 2 suggest), perhaps the low consequentiality of the decision outcome could. In Experiment 3 we addressed this explanation by asking subjects to imagine a hypothetical incident, and to consider how they might verify their memory of this incident when their accuracy should be important (for giving a police statement) versus less important (for telling a story over a family dinner).

\section{Method}

Subjects and design. In this study we collected data online using Amazon's Mechanical Turk (MTurk). For this reason we anticipated that a much larger proportion of subjects than in the previous studies would fail to follow instructions; moreover we used a between-subject design here. For both of these reasons we aimed to recruit a larger initial sample of 300 subjects in this study. A total of 301 MTurk workers ultimately took part in exchange for $\$ 0.80$. Of these, we removed 59 from analyses because they failed our attention check (described below), and a further 59 because they failed to follow the task instructions. The final sample comprised 98 females and 85 males, aged 20-83 $(M=36.80, S D=$ 13.03), and we manipulated consequentiality by randomly allocating each subject to either the family condition $(n=85)$ or the police condition $(n=98)$.

Procedure. In this study we wanted all subjects to consider relatively comparable events, so that we could manipulate the consequentiality of the verification process without confounding the type of event. Therefore, rather than asking subjects to choose a real event from their own lives, we instead asked them to imagine a hypothetical event (see Wade \& Garry, 2005) and to import self-relevant details into that imagination. Specifically, we asked subjects to imagine they were at a party or music festival with a friend, and that together 
they witnessed an incident in which someone was seriously hurt and taken to hospital. We asked them to imagine specific people and places that would make this event plausible for themselves. Subjects then described the event in detail by typing into a text box.

Next, we told subjects to imagine that a few weeks later, they were talking to the same friend about the incident they witnessed together, and that the friend challenged the subject's memory. We told subjects in the police condition to suppose they had been asked to provide a statement to the police about this incident; in contrast, we told those in the family condition to suppose they wanted to tell their family about the incident during an upcoming dinner. In both conditions, subjects read that because their friend had challenged their memory, they felt they should go away and check that it was correct. We told them to assume they had ample to time to do so.

The next part of the procedure was identical to that of Experiment 1, with subjects suggesting five different verification strategies for this single hypothetical event, and rating these strategies on reliability, cost, and likelihood. But this time, we added an attention check to determine whether people correctly remembered the instructions. Specifically, we asked subjects who the intended audience of their memory report was, and offered them four options in a random order: (a) the police; (b) your family; (c) the local newspaper; or (d) your work colleagues. We also added a manipulation check question to ensure that subjects perceived the police scenario as more consequential than the family scenario. Subjects rated on a 7-point scale how important it was to be sure about whether their memory was accurate $(1=$ Not at all important; 7 = Extremely important). After answering all questions, subjects received a written debriefing. 
In Experiments 1 and 2, coding the different strategies that subjects proposed, and including this "type of strategy" variable in the LMM models, made no qualitative difference to the pattern of results. For this reason, and because the type of strategy variable was not directly relevant to our research questions about the cheap strategy bias, we did not code the strategies in Experiment 3.

\section{Results and discussion}

The results of our manipulation check confirmed that subjects in the police condition thought it was more important to know whether their memory was accurate $(M=6.17, S D=0.87)$ than did those in the family condition $(M=$ 5.29, $S D=1.23), t(148.70)=5.49, p<.001, d_{\text {unb }}=0.83$.

The bottom part of Table 1 shows the distribution of reliability and cost ratings among the strategies that subjects in each of the two conditions proposed. Once again, across the dataset there was little association between these two ratings (treating individual strategies as cases, $r(N=915)=-.06, p=$ $.07)$.

Our main analysis of the verification strategies showed that subjects in the police condition reported being more likely to use their strategies, compared with subjects in the family condition. This result provides even further evidence that our manipulation of consequentiality was effective. Once again, the subjects preferred strategies that were reliable and cheap. Yet neither the relationship between Reliability and Likelihood, nor the relationship between Cost and Likelihood, was meaningfully affected by the consequentiality of the scenario.

In LMM terms, we conducted the same initial model as in Experiment 2 (except that we did not include random intercepts for the "type of strategy" 
variable, because we did not code the reported strategies), substituting the Importance variable with Consequentiality (police vs. family). This analysis revealed a main effect of Consequentiality, $b=0.08, S E=0.04, t=2.01$. As in both of our prior studies, Likelihood ratings were again positively associated with Reliability, $b=0.22, S E=0.04, t=5.87$, and negatively associated with Cost, $b=$ $0.46, S E=0.04, t=10.95$. Of particular interest, though, is that there was no meaningful Reliability x Consequentiality interaction, $b=0.02, S E=0.04, t=0.54$, nor a Cost $\mathrm{x}$ Consequentiality interaction, $b=-0.00, S E=0.04, t=0.09$.

A second LMM model once again showed that subjects used a cheap strategy bias. This analysis also confirmed that it did not matter whether people were verifying the memory for their families or for the police, they preferred cheap-and-easy strategies either way. In LMM terms, we repeated the second LMM model from Experiment 2 (except that we did not include random intercepts for strategy-type), substituting the Importance variable from that study with Consequentiality. This model revealed a main effect of Attributedifference-of-betas, $b=-0.16, S E=0.04, t=3.84$, but revealed no Attributedifference-of-betas $\mathrm{x}$ Consequentiality interaction, $b=-0.01, S E=0.04, t=$ 0.27. These analyses provide evidence that consequentiality made little difference to people's desire for cheap-and-easy strategies.

\section{General Discussion}

These three experiments provide new and consistent support for the cheap strategy bias, which guides people's choices of strategies when systematically verifying memories. Individually and collectively, these studies help to rule out several alternative explanations of this bias. In particular, the data show that the bias is neither specific to medical memories nor to childhood 
memories, that it occurs even for personally-important memories, and that it occurs even when the consequences of verifying accurately are themselves important. The cheap strategy bias therefore is robust across different circumstances, even those in which we should expect people to be highly motivated to be accurate.

Our findings on people's strategy choices extend theoretical understanding of the process of source monitoring, by which people discriminate events that truly happened, from events they only imagined, thought or dreamed about (Johnson, Hashtroudi, \& Lindsay, 1993). Much of the vast source monitoring literature has focused on mental heuristics, exploring (for example) phenomenal characteristics that differ between real and imagined events (e.g., Johnson et al., 1988). By contrast, studies such as ours contribute to the relatively small literature on highly systematic and deliberative forms of source monitoring, whereby people shift away from heuristics and instead actively seek evidence. The source monitoring framework proposes that people's likelihood of using systematic (rather than heuristic) source monitoring depends on their motivation and their availability of cognitive resources; however, our data confirm that even strong motivations about accuracy and undivided cognitive resources can push people only so far when it comes to engaging in systematic processes.

An emphasis on using cheap sources of information may be one reason why people develop true nonbelieved memories, ceasing to believe in events that genuinely did occur. Similarly, accessing cheap and unreliable evidence might contribute to people's persistence in believing their real-world false memories. These two different types of belief errors can have repercussions in many real- 
life contexts; for example, if an eyewitness attempts to corroborate their recollection by consulting unreliable sources, then they may become less likely to report valid information, or more likely to report invalid information.

Why, though, might people put such little emphasis on using reliable information, even when mistakes are likely to lead to inaccurate recollections, or indeed to more serious consequences? One possibility is that people simply place so much trust in their memories that, even when challenged, they are unwilling to treat seriously the idea that these memories could be inaccurate. Our findings from Experiment 1 support this interpretation, insofar that the cheap strategy bias was greater for recent memories-which people arguably should be more likely to trust-than for childhood memories. An implication of this interpretation, if it is correct, is that the cheap strategy bias should be weaker, or even reversed (that is, a preference for reliable information over cheap information), among subjects who score highly on measures of memory distrust, such as older adults (Henkel, 2014). Future research addressing this prediction would further contribute to our understanding of the links between memory suggestibility and metamemorial beliefs. In fact, whereas people who trust their memories tend to be less susceptible to suggestion, the present data suggest that these same people might also be less likely to systematically test and validate their memories, meaning that the memory errors they do commit may be more likely to endure (e.g., Van Bergen, Horselenberg, Merckelbach, Jelicic, \& Beckers, 2010).

Some limitations of our method should be noted. First, we instructed subjects in these studies to operationalize "reliability" and "cost" using rather broad definitions - reliability encompassed both trustworthiness and accuracy, 
for example, whereas cost encompassed cognitive, physical and financial expenditure. Future research might consider whether different aspects of these constructs have greater weight than others in determining which strategies are used. Second, all of our experiments involved subjects proposing strategies they might use in hypothetical scenarios. Another important issue to address is which strategies people actually turn to when their memories are challenged. It may be, for example, that subjects in these studies fail to envisage how they would truly feel if one of their self-defining memories were challenged, and the lengths to which they might actually go to test the challenge (Wilson \& Gilbert, 2003). This issue is particularly pertinent to Experiment 3, where subjects imagined a hypothetical event rather than recalling genuine autobiographical memories. The use of a hypothetical event in that experiment allowed us strong experimental control, but it creates a further point of difference from the real-life task of verifying memories. In the legal psychology literature, recent studies have tackled similar questions about what kinds of sources people truly turn to when they attempt to corroborate alibis (e.g., Olson \& Charman, 2012). We suggest that the inventive methods used in these alibi studies could be adapted to help better illuminate the real-world process of verifying memories. 


\section{References}

Allport, G. (1954). The nature of prejudice. Oxford, England: Addison-Wesley. Angele, B., Tran, R., \& Rayner, K. (2013). Parafoveal-foveal overlap can facilitate ongoing word identification during reading: Evidence from eye movements. Journal of Experimental Psychology: Human Perception and Performance, 39, 526.

Arbuthnott, K. D., Kealy, K. L. K., \& Ylioja, S. (2008). Judgement of confidence in childhood memories. Applied Cognitive Psychology, 22, 953-978.

Bluck, S. \& Alea, N. (2008). Remembering being me: the self-continuity function of auobiographical memory in younger and older adults. In F. Sani, (Ed.), Self-continuity: Individual and collective perspectives (pp.55-70). New York: Psychology Press.

Chabris, C., \& Simons, D. (2015, February 10). How not to be the next Brian Williams: Ten ways to avoid false memories. Retrieved from www.slate.com/articles/health_and_science/science/2015/02/false_memor ies_of_brian_williams_memory_experts_chabris_and_simons_tips.html.

Clark, A., Nash, R. A., Fincham, G., \& Mazzoni, G. (2012). Creating non-believed memories for recent autobiographical events. PLoS ONE, e32998.

Eagly. A. H., \& Chaiken, S. (1993). The psychology of attitudes. Fort Worth, TX: Harcourt, Brace, \& Janovich.

Fiske, S. T., \& Taylor, S. (1984). Social cognition. New York, NY: McGraw Hill.

Greenberg, D. L. (2004). President Bush's false 'flashbulb' memory of 9/11/01. Applied Cognitive Psychology, 18, 363-370.

Henkel, L. A. (2014). Memory trust and distrust in elderly eyewitnesses: To what extent do older adults doubt their memories? In M. P. Toglia, D. F. Ross, J. 
Pozzulo, \& E. Pica (Eds.), The elderly eyewitness in court (pp. 232-262). Hove: Psychology Press.

Johnson, M. K., Foley, M. A., Suengas, A. G., \& Raye, C. L. (1988). Phenomenal characteristics of memories for perceived and imagined autobiographical events. Journal of Experimental Psychology: General, 117, 371-376.

Johnson, M. K., Hashtroudi, S., \& Lindsay, D. S. (1993). Source monitoring. Psychological Bulletin, 114, 3-28.

Kemp, S., \& Burt, C. D. B. (2006). Memories of uncertain origin: Dreamt or real? Memory, 14, 87-93.

Kool, W., McGuire, J. T., Rosen, Z. B., \& Botvinick, M. M. (2010). Decision making and the avoidance of cognitive demand. Journal of Experimental Psychology: General, 139, 665-682.

Mason, J. (2008, March 25). Hillary Clinton calls Bosnia sniper story a mistake. Retrieved from www.reuters.com/article/us-usa-politics-clintonidUSN2540811420080326.

Mazzoni, G., Clark, A., \& Nash, R. A. (2014). Disowned recollections: Denying true experiences undermines belief in occurrence but not judgments of remembering. Acta Psychologica, 145, 139-146.

Mazzoni, G., Scoboria, A., \& Harvey, G. (2010). Nonbelieved memories. Psychological Science, 21, 1334-1340.

McNally, R. J. (2012). Explaining "memories" of space alien abduction and past lives: An experimental psychopathology approach. Journal of Experimental Psychopathology, 1, 2-16. 
Merckelbach, H., Van Roermund, H., \& Candel, I. (2007). Effects of collaborative recall: Denying true information is as powerful as suggesting misinformation. Psychology, Crime \& Law, 13, 573-581.

Nash, R. A., Berkowitz, S. R., \& Roche, S. (under review). Public attitudes on the ethics of deceptively planting false memories to motivate healthy behavior. Manuscript submitted for publication.

Nash, R. A., \& Takarangi, M. K. T. (2011). Reconstructing alcohol-induced memory blackouts. Memory, 19(6), 566-573.

Newman, E. J., Berkowitz, S. R., Nelson, K. J., Garry, M., \& Loftus, E. F. (2011). Attitudes about memory dampening drugs depend on context and country. Applied Cognitive Psychology, 25, 675-681.

Olson, E. A., \& Charman, S. D. (2012). 'But can you prove it?'-examining the quality of innocent suspects' alibis. Psychology, Crime \& Law, 18, 453-471.

Otgaar, H., Scoboria, A., \& Mazzoni, G. (2014). On the existence and implications of nonbelieved memories. Current Directions in Psychological Science, 23, 349-354.

Otgaar, H., Scoboria, A., \& Smeets, T. (2013). Experimentally evoking nonbelieved memories for childhood events. Journal of Experimental Psychology: Learning, Memory, \& Cognition, 39, 717-730.

Ross, M. (1997). Validating memories. In N. L. Stein, P. A. Ornstein, B. Tversky, \& C. Brainerd (Eds.), Memory for everyday and emotional events (pp. 49-81). Hillsdale, NJ: Erlbaum.

Ross, M., \& Newby, I. R. (1996). Distinguishing memory from fantasy. Psychological Inquiry, 7, 173-177.

Scoboria, A., Boucher, C., \& Mazzoni, G. (2015). Reasons for withdrawing belief in 
vivid autobiographical memories. Memory, 23, 545-562.

Selinger, J. C., O’Connor, S. M., Wong, J. D., \& Donelan, J. M. (2015). Humans can continuously optimize energetic cost during walking. Current Biology, 25, $2452-2456$.

Sheen, M., Kemp, S., \& Rubin, D. (2001). Twins dispute memory ownership: A new false memory phenomenon. Memory \& Cognition, 29, 779-788.

Sheldon, K. M., Elliot, A. J., Kim, Y., \& Kasser, T. (2001). What's satisfying about satisfying events? Comparing ten candidate psychological needs. Journal of Personality \& Social Psychology, 80, 325-339.

Sparrow, W. A., \& Newell, K. M. (1998). Metabolic energy expenditure and the regulation of movement economy. Psychonomic Bulletin \& Review, 5, 173196.

Sutin, A. R., \& Robins, R. W. (2008). When the "I" looks at the "Me": Autobiographical memory, visual perspective, and the self. Consciousness and Cognition, 17, 1386-1397.

Van Bergen, S., Horselenberg, R., Merckelbach, H., Jelicic, M., \& Beckers, R. (2010). Memory distrust and acceptance of misinformation. Applied Cognitive Psychology, 24, 885-896.

Wade, K. A., \& Garry, M. (2005). Strategies for verifying false autobiographical memories. American Journal of Psychology, 118, 587-602.

Wade, K. A., Nash, R. A., \& Garry, M. (2014). People consider reliability and cost when verifying their autobiographical memories. Acta Psychologica, 146, 2834.

Wilson, T. D., \& Gilbert, D. T. (2003). Affective forecasting. Advances in Experimental Social Psychology, 35, 345-411. 
Zipf, G. K. (1949/1972). Human behavior and the principle of least effort: An introduction to human ecology. New York: Hafner. 
Table 1. Distribution of reliability and cost ratings for the strategies suggested by subjects in each condition of Experiment 1, 2, and 3.

\begin{tabular}{|c|c|c|c|c|c|c|c|}
\hline \multirow[t]{2}{*}{ Experiment 1} & \multirow{2}{*}{$\begin{array}{l}\text { Cost } \\
\text { rating }\end{array}$} & \multicolumn{6}{|c|}{ Reliability rating } \\
\hline & & 1 & 2 & 3 & 4 & 5 & Total \\
\hline \multirow{6}{*}{$\begin{array}{l}\text { Childhood } \\
\text { memory }\end{array}$} & 1 & $3.4 \%$ & $8.4 \%$ & $10.0 \%$ & $10.0 \%$ & $12.4 \%$ & $44.2 \%$ \\
\hline & 2 & $1.2 \%$ & $3.4 \%$ & $3.6 \%$ & $6.0 \%$ & $4.0 \%$ & $18.2 \%$ \\
\hline & 3 & $1.0 \%$ & $1.8 \%$ & $3.6 \%$ & $3.0 \%$ & $3.8 \%$ & $13.2 \%$ \\
\hline & 4 & $1.4 \%$ & $2.8 \%$ & $3.2 \%$ & $1.4 \%$ & $4.4 \%$ & $13.2 \%$ \\
\hline & 5 & $1.6 \%$ & $2.0 \%$ & $2.4 \%$ & $2.2 \%$ & $3.0 \%$ & $11.2 \%$ \\
\hline & Total & $8.6 \%$ & $18.4 \%$ & $22.8 \%$ & $22.6 \%$ & $27.6 \%$ & \\
\hline \multirow[t]{6}{*}{ Recent memory } & 1 & $1.2 \%$ & $5.6 \%$ & $9.4 \%$ & $13.8 \%$ & $20.0 \%$ & $50.0 \%$ \\
\hline & 2 & $0.8 \%$ & $3.0 \%$ & $4.6 \%$ & $5.0 \%$ & $6.6 \%$ & $20.0 \%$ \\
\hline & 3 & $0.6 \%$ & $1.4 \%$ & $2.4 \%$ & $3.8 \%$ & $2.8 \%$ & $11.0 \%$ \\
\hline & 4 & $0.4 \%$ & $1.8 \%$ & $1.4 \%$ & $2.8 \%$ & $4.0 \%$ & $10.4 \%$ \\
\hline & 5 & $1.4 \%$ & $0.8 \%$ & $1.6 \%$ & $2.2 \%$ & $2.6 \%$ & $8.6 \%$ \\
\hline & Total & $4.4 \%$ & $12.6 \%$ & $19.4 \%$ & $27.6 \%$ & $36.0 \%$ & \\
\hline \multirow[t]{2}{*}{ Experiment 2} & \multirow{2}{*}{$\begin{array}{c}\text { Cost } \\
\text { rating }\end{array}$} & \multicolumn{6}{|c|}{ Reliability rating } \\
\hline & & 1 & 2 & 3 & 4 & 5 & Total \\
\hline \multirow{6}{*}{$\begin{array}{l}\text { Important } \\
\text { memory }\end{array}$} & 1 & $0.0 \%$ & $4.2 \%$ & $11.3 \%$ & $13.8 \%$ & $20.6 \%$ & $50.0 \%$ \\
\hline & 2 & $0.6 \%$ & $4.2 \%$ & $4.4 \%$ & $3.3 \%$ & $6.7 \%$ & $19.2 \%$ \\
\hline & 3 & $0.8 \%$ & $1.9 \%$ & $2.9 \%$ & $3.8 \%$ & $6.2 \%$ & $15.6 \%$ \\
\hline & 4 & $0.0 \%$ & $1.3 \%$ & $2.1 \%$ & $2.3 \%$ & $4.4 \%$ & $10.2 \%$ \\
\hline & 5 & $0.4 \%$ & $1.0 \%$ & $0.8 \%$ & $1.0 \%$ & $1.9 \%$ & $5.0 \%$ \\
\hline & Total & $1.7 \%$ & $12.7 \%$ & $21.5 \%$ & $24.2 \%$ & $39.8 \%$ & \\
\hline \multirow[t]{5}{*}{ Trivial memory } & 1 & $1.9 \%$ & $6.7 \%$ & $11.2 \%$ & $16.7 \%$ & $14.2 \%$ & $50.8 \%$ \\
\hline & 2 & $0.0 \%$ & $3.1 \%$ & $3.7 \%$ & $5.2 \%$ & $4.2 \%$ & $16.2 \%$ \\
\hline & 3 & $0.4 \%$ & $1.5 \%$ & $4.8 \%$ & $4.8 \%$ & $3.3 \%$ & $14.8 \%$ \\
\hline & 4 & $1.0 \%$ & $1.7 \%$ & $2.1 \%$ & $1.3 \%$ & $4.0 \%$ & $10.2 \%$ \\
\hline & 5 & $0.6 \%$ & $1.5 \%$ & $1.7 \%$ & $1.0 \%$ & $3.3 \%$ & $8.1 \%$ \\
\hline
\end{tabular}




\begin{tabular}{|c|c|c|c|c|c|c|c|}
\hline & Total & $3.8 \%$ & $14.6 \%$ & $23.5 \%$ & $29.0 \%$ & $29.0 \%$ & \\
\hline \multirow[t]{2}{*}{ Experiment 3} & \multirow{2}{*}{$\begin{array}{c}\text { Cost } \\
\text { rating }\end{array}$} & \multicolumn{6}{|c|}{ Reliability rating } \\
\hline & & 1 & 2 & 3 & 4 & 5 & Total \\
\hline \multirow[t]{6}{*}{ Family } & 1 & $0.7 \%$ & $6.8 \%$ & $16.0 \%$ & $17.6 \%$ & $20.5 \%$ & $61.6 \%$ \\
\hline & 2 & $0.5 \%$ & $0.9 \%$ & $5.2 \%$ & $7.5 \%$ & $4.2 \%$ & $18.4 \%$ \\
\hline & 3 & $0.2 \%$ & $1.4 \%$ & $4.5 \%$ & $3.1 \%$ & $2.8 \%$ & $12.0 \%$ \\
\hline & 4 & $0.0 \%$ & $0.2 \%$ & $2.8 \%$ & $1.6 \%$ & $1.2 \%$ & $5.9 \%$ \\
\hline & 5 & $0.5 \%$ & $0.5 \%$ & $0.7 \%$ & $0.2 \%$ & $0.2 \%$ & $2.1 \%$ \\
\hline & Total & $1.9 \%$ & $9.9 \%$ & $29.2 \%$ & $30.1 \%$ & $28.9 \%$ & \\
\hline \multirow[t]{6}{*}{ Police } & 1 & $2.7 \%$ & $7.6 \%$ & $13.3 \%$ & $17.1 \%$ & $13.5 \%$ & $54.1 \%$ \\
\hline & 2 & $0.2 \%$ & $2.2 \%$ & $7.6 \%$ & $6.7 \%$ & $3.1 \%$ & $19.8 \%$ \\
\hline & 3 & $0.2 \%$ & $1.8 \%$ & $3.9 \%$ & $6.3 \%$ & $3.1 \%$ & $15.3 \%$ \\
\hline & 4 & $0.2 \%$ & $1.2 \%$ & $2.4 \%$ & $2.0 \%$ & $1.2 \%$ & $7.1 \%$ \\
\hline & 5 & $0.0 \%$ & $0.4 \%$ & $1.0 \%$ & $1.2 \%$ & $1.0 \%$ & $3.7 \%$ \\
\hline & Total & $3.3 \%$ & $13.3 \%$ & $28.2 \%$ & $33.5 \%$ & $21.8 \%$ & \\
\hline
\end{tabular}




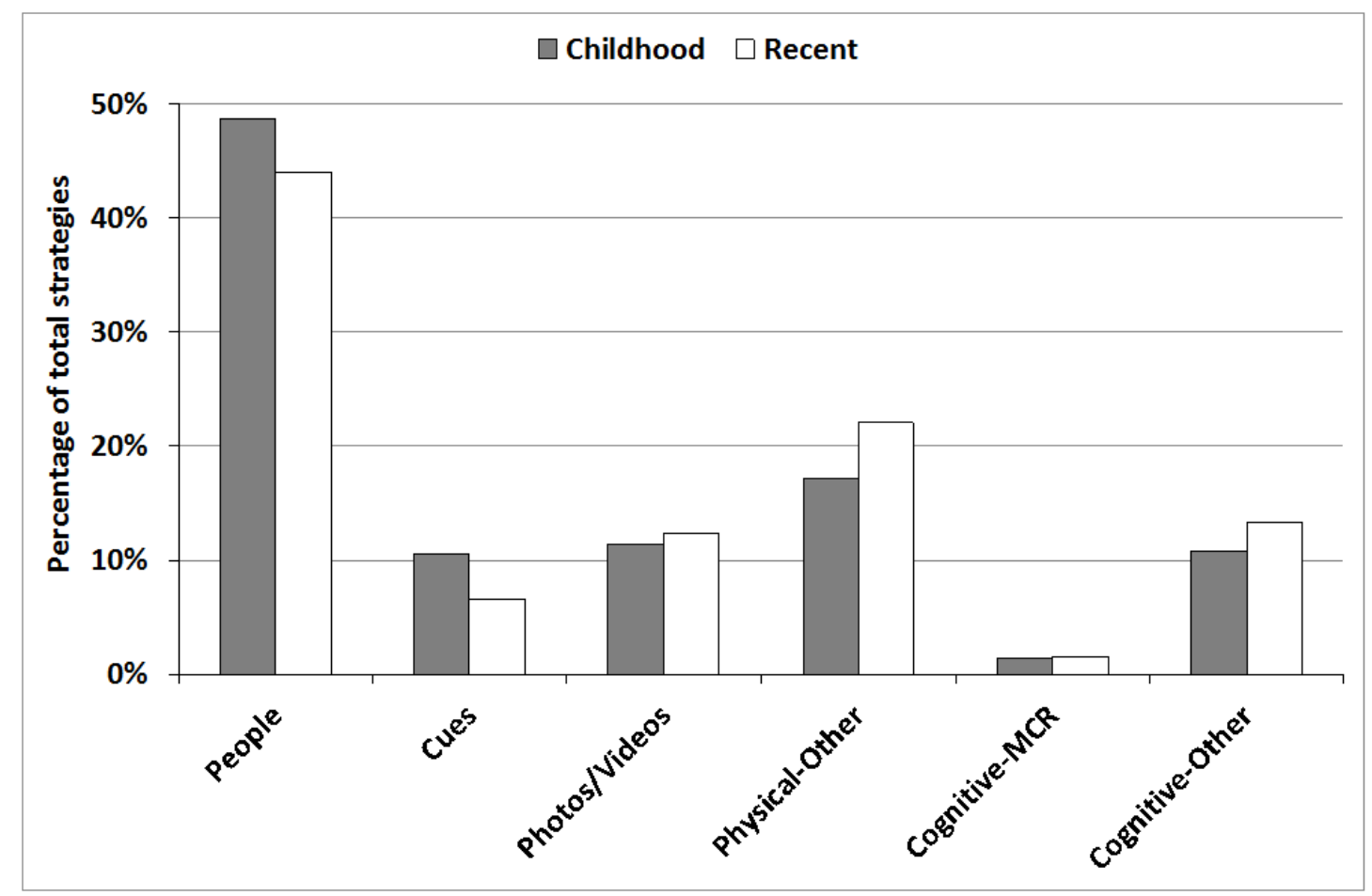

Figure 1. Types of strategies proposed by subjects to verify childhood memories and recent memories in Experiment $1 . \mathrm{MCR}=$ Mental context reinstatement. 


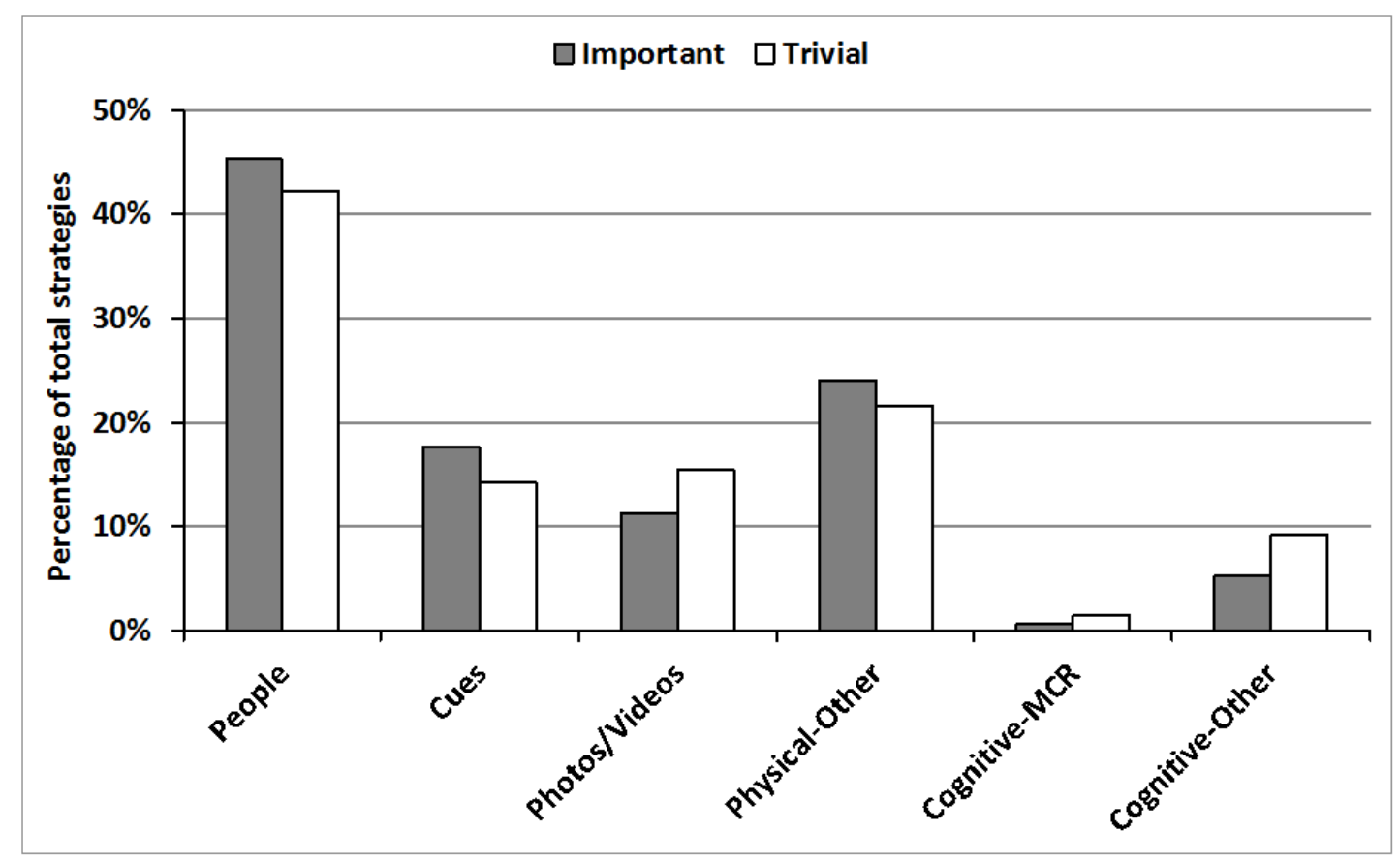

Figure 2. Types of strategies proposed by subjects to verify important memories and trivial memories in Experiment 2. $\mathrm{MCR}=$ Mental context reinstatement. 
Supplemental Materials

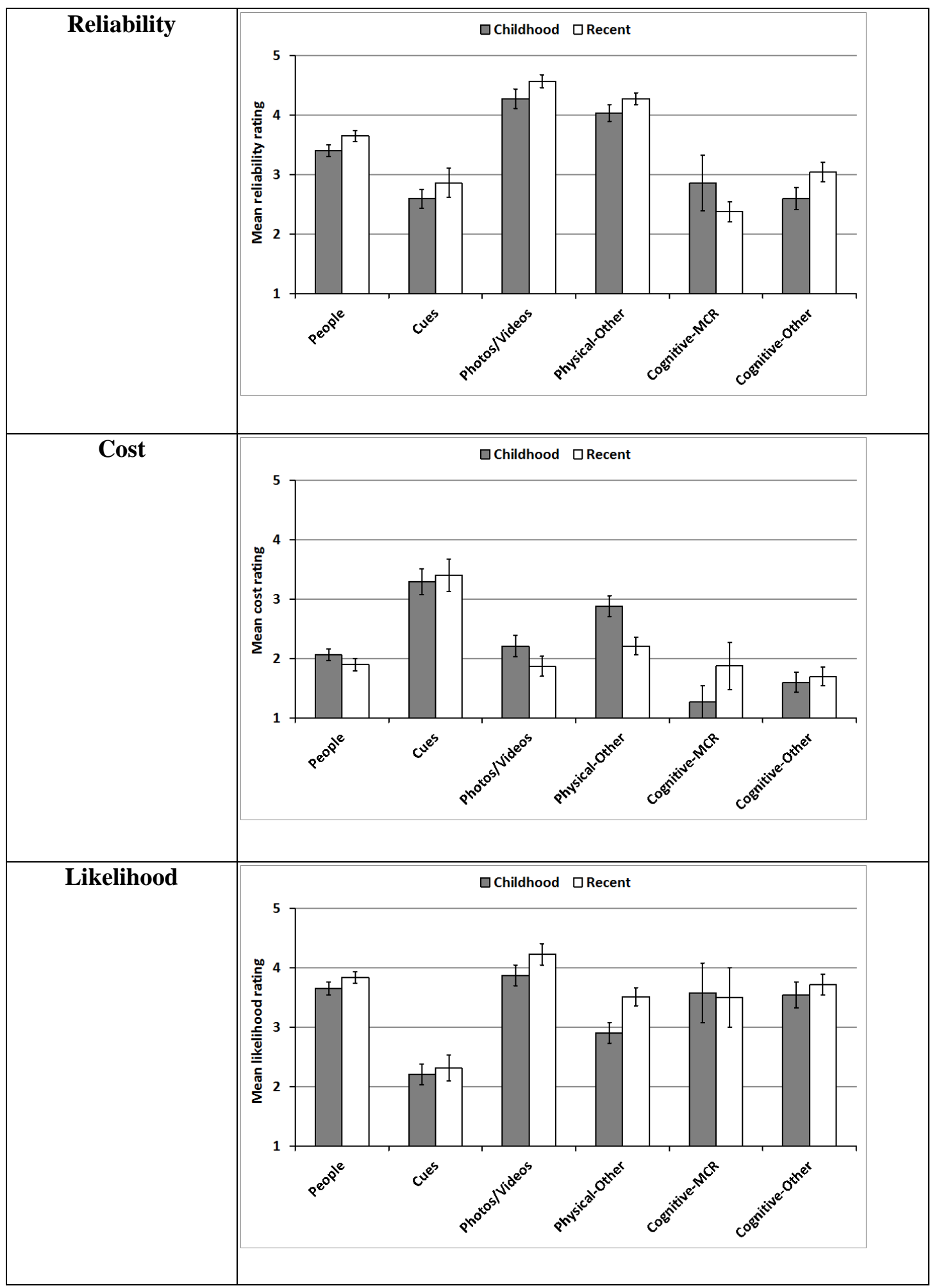

Figure S1. Mean ratings of reliability (top panel), cost (middle panel), and likelihood (bottom panel) for each type of strategy in Experiment 1. Error bars are standard errors. 


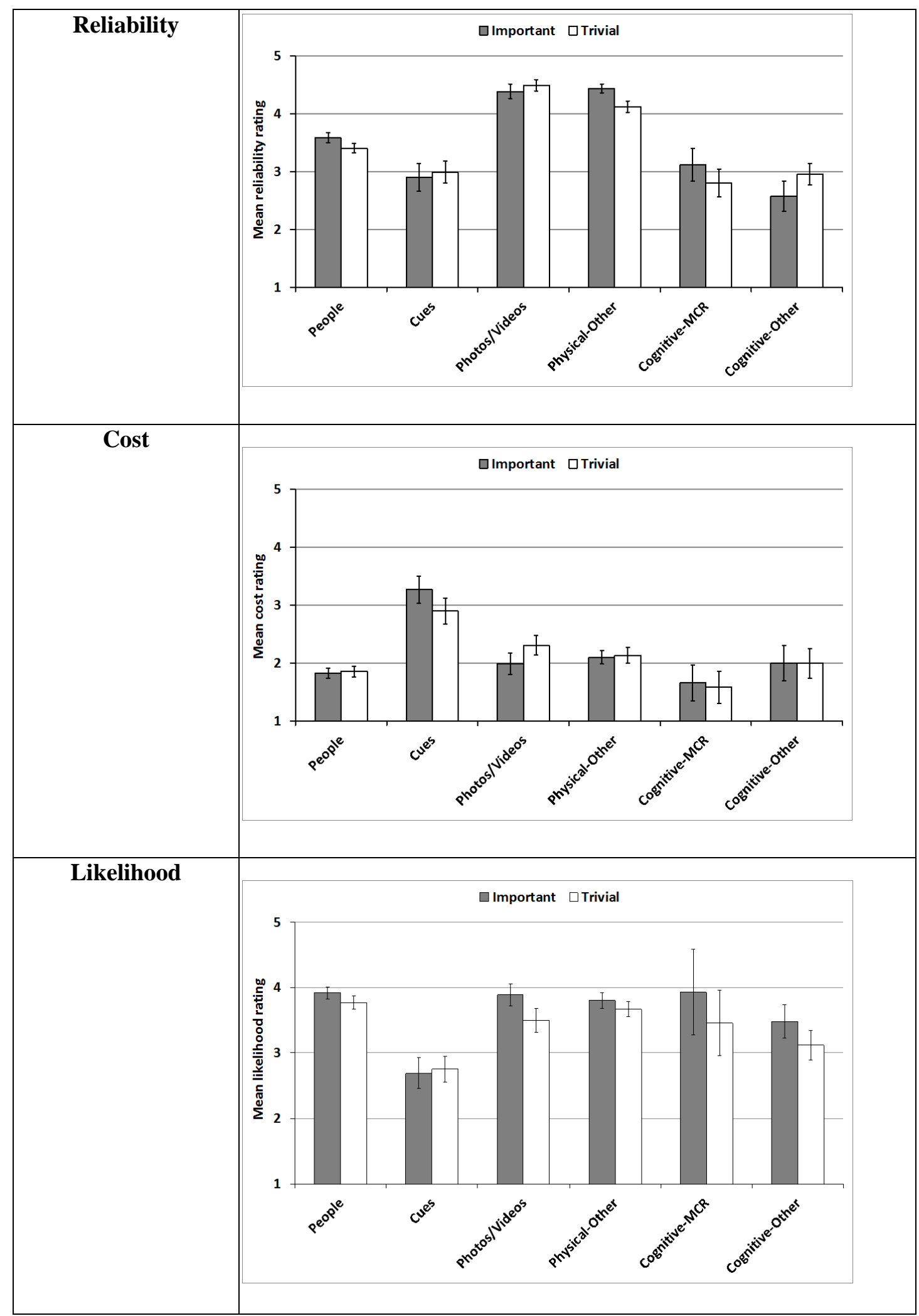

Figure S2. Mean ratings of reliability (top panel), cost (middle panel), and likelihood (bottom panel) for each type of strategy in Experiment 2. Error bars are standard errors. 